\title{
A Broadband Circularly Polarized Antenna with Low-Profile and Wide Axial Ratio Beamwidth
}

\author{
Madhuri SAHAL ${ }^{1}$, Vivekanand TIWARI ${ }^{1}$, Dinesh YADAV ${ }^{1, *}$, \\ Deepak BHATNAGAR ${ }^{2}$ and Tejpal ${ }^{1}$ \\ ${ }^{I}$ Department of Electronics \& Communication Engineering, Manipal University Jaipur, \\ Jaipur, Rajasthan 303007, India \\ ${ }^{2}$ Microwave Lab, Department of Physics, University of Rajasthan, India
}

('Corresponding author’s e-mail: dinesh.yadav@jaipur.manipal.edu)

Received: 14 February 2021, Revised: 21 April 2021, Accepted: 5 April 2021

\begin{abstract}
In this work, the design and the characterization of a broadband circular polarized monopole having low-profile and wide axial ratio beamwidth were presented. The antenna was designed on readily available, inexpensive glass-reinforced epoxy substrate having an overall size of $0.56 \lambda_{0} \times 0.50 \lambda_{0} \times 0.029 \lambda_{0}$ (at center frequency $5.5 \mathrm{GHz}$ ). The proposed antenna was a modification of a square-shaped monopole antenna, which incorporates a pair of peripheral slits and an off-center slot for a elliptical polarized radiation. A v-shaped notch below the feed line was introduced and extended as antenna ground to generate broadband circular polarization characteristics. The $-10 \mathrm{~dB}$ reflection coefficient bandwidth and $3-\mathrm{dB}$ axial-ratio bandwidth of the proposed antenna were measured to be of 47.6 and $27 \%$, respectively. The 3-dB axial ratio beamwidth of the antenna was $93.5^{\circ}$. The antenna proposed in this work covers multiple application frequency bands including HiperLAN/2 IEEE 802.11a (5.15 - $5.35 \mathrm{GHz} / 5.47$ $5.725 \mathrm{GHz})$ band, WLAN frequency band $(5.1-5.9 \mathrm{GHz})$, C-band uplink $(5.925-6.325 \mathrm{GHz})$ and part of military application band $(4.75-4.99 \mathrm{GHz})$.
\end{abstract}

Keywords: Circular polarized, Broadband, Axial ratio, Wide beamwidth, Low-profile

\section{Introduction}

Recently, there has been a profound interest in broadband circular polarized (CP) antennas so that a single antenna can be used for multi-service radio communication systems. The communication link becomes robust to adverse weather conditions and channel impairments (multipath fading, ionospheric rotation or hindrance of LoS link) and polarization mismatch problems with the use of CP antennas. Therefore, broadband CP antennas that operate on multiple application bands are the key for future wireless communication systems. Antennas for wireless applications need to be compact and low-profile for easy integration into wireless portable devices. Also, the antennas for wireless communication must have good spatial coverage. Therefore, designing broadband circular polarized antennas having lowprofile and wide axial ratio beamwidth is relevant.

A number of researchers have addressed the widebeam design for circular polarized antennas. For example, $\mathrm{Ng}$ et al. [1] reported a wide axial ratio beamwidth of $121^{\circ}$ which was achieved by using an elliptical vertical patch antenna through TACONIC laminate as substrate. Though the proposed design had wide CP beamwidth, it has a narrowband circular polarized $(3.48 \%$ at $3.845 \mathrm{GHz})$. Wang et al. [2] have demonstrated a simple and compact structure using parasitic rectangular patches coupled to a central modified-rectangular patch. Paper reports a wide axial ratio beamwidth of $188^{\circ}$ using F4BK350 substrate, but the antenna has narrowband $\mathrm{CP}$ characteristic $(0.63 \%$ at $1.57 \mathrm{GHz})$. 
Zhang et al. [3] reported a coaxially fed circular patch and parasitic ring electromagnetically coupled to another square patch to generate wide-beam linearly polarized radiation [3]. Although the antenna has exhibited high gain of $6.2 \mathrm{~dB}$, it has a narrow impedance bandwidth at $2.37 \mathrm{GHz}$ and linearly polarized radiation characteristic. A square patch integrated with 4-asymmetric circular patches have been used by Nasimuddin et al. [4] to generate circular polarization characteristics. With a compact size of $0.373 \lambda_{0} \times 0.373 \lambda_{0} \times 0.016 \lambda_{0}$, a wide axial ratio beamwidth of $180^{\circ}$ was attained. The antenna has narrowband CP characteristic (1.5\% AR bandwidth). Chen et al. [5] have demonstrated the use of meander line ring cavity structure for cross-polarization suppression. Though the antenna exhibited wide axial ratio beamwidth of $190^{\circ}$, the $3-\mathrm{dB}$ gain beamwidth was only $109^{\circ}$. Moreover, the antenna exhibited narrowband CP characteristic (8.5\% AR bandwidth at $1.2 \mathrm{GHz}$ ). Sitompul et al. [6] have proposed a modified-circular wide slot antenna for nanosatellite applications that achieved an AR bandwidth of 327.5 $\mathrm{GHz}(14.88 \%)$ at $2.2 \mathrm{GHz}$. Though the antenna showed a gain of $4.5 \mathrm{dBic}$ at $2.2 \mathrm{GHz}$, it has a large volume of $100 \times 100 \times 1.6 \mathrm{~mm}^{3}\left(0.78 \lambda_{0} \times 0.78 \lambda_{0} \times 0.012 \lambda_{0}\right)$. Though the above designs [1-6] achieved CP characteristics over wide beam, they exhibit narrowband CP characteristics. Future wireless applications demand the use of wide beam CP antennas that demonstrate wideband CP characteristic.

Literature suggests that much work on wideband CP antennas has been carried out. Recently, a CPW-fed wide slot antenna exhibiting circular polarized radiation for wireless data transfer has been proposed by Birwal et al. [7]. The antenna achieves dual sense circular polarized radiation. The switching between the polarization is achieved by applying the feed at one of the 2 ports. The antenna shows wideband $\mathrm{CP}$ within the frequency range from 2.67 to $5.89 \mathrm{GHz}$, with isolation more than $17 \mathrm{~dB}$. However, the gain fluctuation over the $\mathrm{CP}$ band is more than $2 \mathrm{~dB}$. A patch loaded with $\mathrm{S}$-shaped transmission line was designed by Mo and Zhang [8] to achieve wide axial ratio beamwidth of $212^{\circ}$ in Eplane and $217^{\circ}$ in H-plane. The proposed antenna design had low gain (peak value of $1.25 \mathrm{dBi}$ ) and large in volume $\left(\pi\left(0.93 \lambda_{0}\right)^{2} \times 0.062 \lambda_{0}\right)$ at $5.8 \mathrm{GHz}$.

Liu et al. [9] have designed a compact $\left(0.34 \lambda_{0} \times 0.34 \lambda_{0} \times 0.033 \lambda_{0}\right)$ structure that displayed a wide axial ratio beamwidth of $270^{\circ}$ in E-plane and $274^{\circ}$ in H-plane. The antenna demonstrates wide $3 \mathrm{~dB}$ axial ratio (AR) bandwidth of $21.6 \%(2.5-3.17 \mathrm{GHz})$ and $10 \mathrm{~dB}$ impedance bandwidth of $3.2 \%(3.03-3.13 \mathrm{GHz})$. Although the reported antenna had achieved a wide axial ratio bandwidth, but the AR bandwidth that is overlapping with $-10 \mathrm{~dB}$ impedance bandwidth is only $3.2 \%$. Moreover, the design attained a low peak gain of $1.39 \mathrm{dBic}$. Hu et al. [10] demonstrated the use of crossed-dipole fed structure using a bow-tie shaped feed line loaded with bent-slots to generate broadband CP characteristic. However, the design is complex and uses a vortex-shaped radiator, which is large in volume $\left(1.06 \lambda_{0} \times 1.06 \lambda_{0} \times 0.192 \lambda_{0}\right)$. The designing of compact, low-profile, broadband circular polarized antennas having wide AR beamwidth for modern wireless applications, is a challenge.

In this communication, design and performance of a low-profile, low-cost antenna structure printed on readily available FR4 substrate has been presented for implementing wide beam, broadband circular polarized characteristics. The modified diagonally fed square-shaped monopole antenna has been used to generate the broad beam CP characteristics. For achieving wideband CP characteristic, a v-shaped notch below the feed line is extended as antenna ground plane. The proposed CP antenna achieved an axial ratio less than $1 \mathrm{~dB}$ over $800 \mathrm{MHz}$ of the WLAN band $(5.1-5.9 \mathrm{GHz})$ and the minimum value of axial ratio achieved is 0.148 at $5.5 \mathrm{GHz}$ frequency. The axial ratio bandwidth covers the HiperLAN/2 IEEE 802.11a $(5.15-5.35 \mathrm{GHz} / 5.47-5.725 \mathrm{GHz})$ band, WLAN frequency band (5.1 - $5.9 \mathrm{GHz})$, and C-band uplink $(5.925-6.325 \mathrm{GHz})$. The proposed antenna also covers the part of military application band ranging from $4.75-4.99 \mathrm{GHz}$.

\section{Materials and methods}

\section{Antenna design}

The antenna is designed on an easily available glass-reinforced epoxy substrate $\left(\epsilon_{\mathrm{r}}=4.4\right.$ and $\tan \delta=$ 0.025 ) having dimensions of $31 \times 27.5 \times 1.6 \mathrm{~mm}^{3}$ (as depicted in Figure 1). The optimum values of dimensions of the proposed CP antenna are listed in Table 1. The proposed design is evolved through a sequential modification in 4 stages as illustrated in Figure 2. 

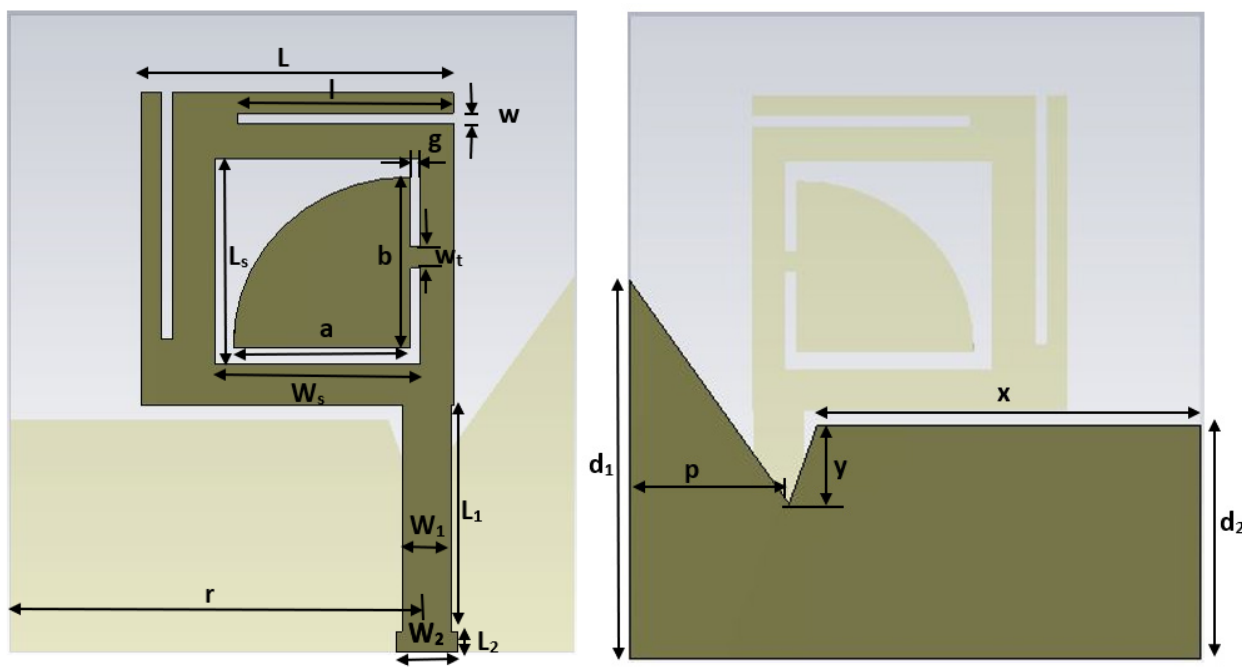

Figure 1 Proposed broadband CP Antenna configuration (a) top view and (b) bottom view.

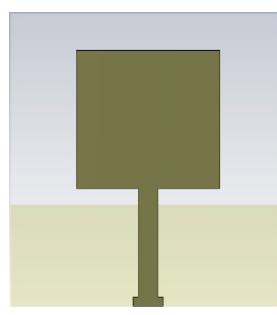

Stage 1

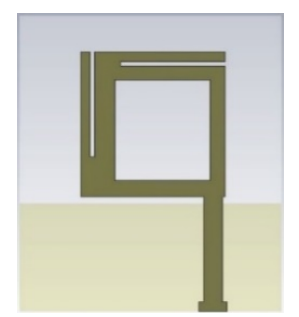

Stage 2

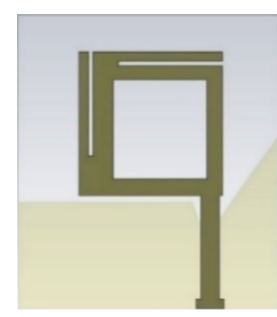

Stage 3

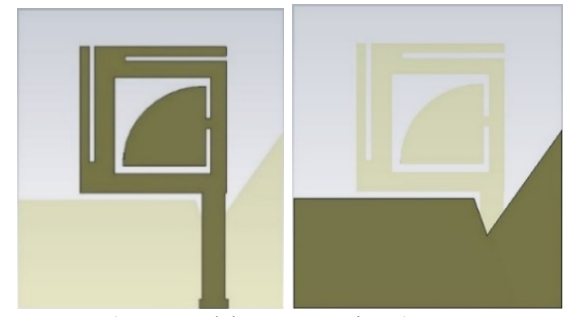

Stage 4 (top and bottom view)

Figure 2 Design stages of the proposed broadband, widebeam CP antenna.

A basic square-shaped antenna (Stage 1, Figure 2) is initially designed for operation in the desired frequency range (center frequency $5 \mathrm{GHz}$ ) under the constraint of overall substrate dimensions. The antenna is fed by using $50 \Omega$ stepped microstrip line feed on a rectangular ground having dimensions $10.3 \times 27.5 \mathrm{~mm}^{2}$. The radiating patch and ground plane have a gap ' $\mathrm{g}$ ' $=0.2 \mathrm{~mm}$. The ground plane and the square patch constitute an electric monopole, whose resonance frequency is given by the empirical formula using Eq. (1) with the symbols carrying their usual meanings [11].

$f_{r}=\frac{14.4}{L_{p}+L_{g}+g+R_{p}+R_{g}} G H z$

$R_{p}=\frac{\text { patch area }}{2 \pi L_{p} \sqrt{\varepsilon_{r, e f f}}}=\frac{L \times L}{2 \pi L \sqrt{\varepsilon_{r, e f f}}} m m$

$R_{g}=\frac{\text { ground plane area }}{2 \pi L_{g} \sqrt{\varepsilon_{r, e f f}}}=\frac{10.3 \times 27.5}{2 \pi(10.3) \sqrt{\varepsilon_{r, e f f}}} \mathrm{~mm}$

Using the above Eqs. (2) - (3), the obtained value of $R_{p}$ and $R_{g}$ are $L / 10.32$ and $2.66 \mathrm{~mm}$ respectively. For resonant frequency of $5 \mathrm{GHz}$ and ground plane length $\mathrm{L}_{\mathrm{g}}=10.3 \mathrm{~mm}$, the computed length of square patch (L) using Eq. (1) is $14.6 \mathrm{~mm}$. The antenna (Stage 1) is linearly polarized as axial 
ratio is higher than $18 \mathrm{~dB}$. The improvement in the impedance matching and circular polarization characteristics at each design stage is depicted in Figure 3.

In the next step (Stage 2) to achieve elliptical polarization, the square patch is loaded with a centrally offset square slot. Further, the square patch is modified by introducing 2 orthogonal slits of dimensions $l \times \mathrm{W}$ at a distance of $1 \mathrm{~mm}$ from the edge on the diagonally opposite corner with respect to feed. Introduction of the slits leads to CP generation in frequency band at $4.5 \mathrm{GHz}$. The antenna is then loaded by using an off-center placed nearly-square slot having dimensions $\mathrm{L}_{\mathrm{s}} \times \mathrm{W}_{\mathrm{s}}$ for wide $\mathrm{CP}$ beam characteristic. This results in elliptical polarization generation over the frequencies $4.5-5.3$ and $6.8-7.5$ $\mathrm{GHz}$ bands. The combined effect of the slits and slot as shown in Figure 3(b). It also shows the presence of elliptically polarized radiation in $4.5-5.3 \mathrm{GHz}$ and $\mathrm{CP}$ radiation in bands at 3.5 and $7.5 \mathrm{GHz}$. Though elliptical polarization is achieved, the impedance matching in the desired band degrades.

For improving the impedance matching characteristic in the desired frequency range and improving the axial ratio characteristic, a v-shaped notch is cut just below the feed line and extended as the ground plane of antenna on one side (Stage 3). This results in asymmetrical distribution of surface current in antenna ground plane as demonstrated in Figure 4. The asymmetrical current distribution in the antenna ground is responsible for wideband CP generation (to be discussed in section 2.2). This leads to an improvement in impedance matching characteristics in the frequency range $6-7.5 \mathrm{GHz}$ as depicted in Figure 3(a). Hence, the central elliptical polarized band ranging from $4.5-5.3 \mathrm{GHz}$ combines with the upper $\mathrm{CP}$ band at $7.5 \mathrm{GHz}$ for the proposed structure in stage 3 . Thus, a wideband elliptical polarized characteristic is achieved for the frequency ranges $3.5-3.65,3.75-3.9,4.15-6.6$ and $8.25-8.4 \mathrm{GHz}$ as illustrated in Figure 3(b).

For further improvement in the impedance matching characteristic and CP response in the desired band, a quarter section of inductively coupled elliptical patch having semi-major axis $(\mathrm{a}=9.3 \mathrm{~mm})$ and semi-minor axis $(b=8.8 \mathrm{~mm})$ is introduced in the slot (Stage 4). This further improves the impedance matching characteristic over the frequencies $4.6-6.3 \mathrm{GHz}$ and leads to the generation of circular polarization characteristic as depicted in Figures 3(a) and 3(b), respectively.

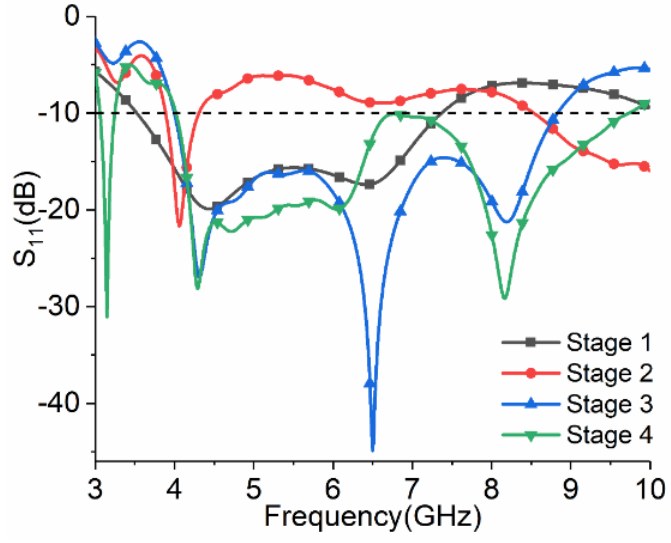

(a)

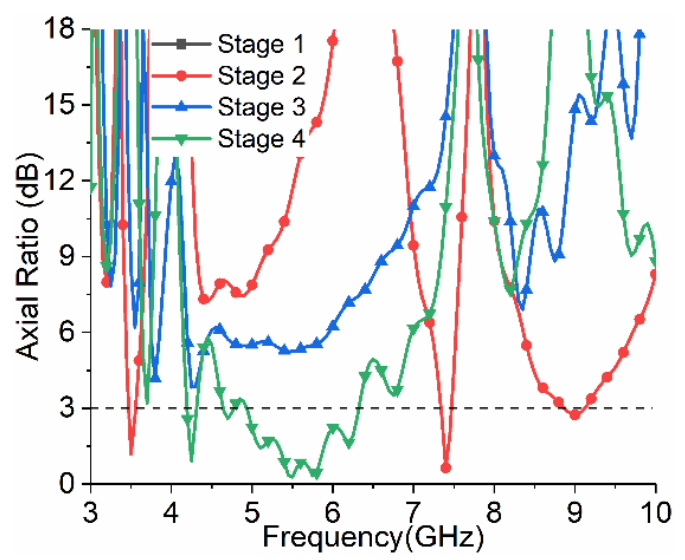

(b)

Figure 3 (a) Variation in reflection coefficient with frequency, (b) Variation in axial ratio with frequency.

Table 1 Optimized dimensions of proposed CP antenna. 


\begin{tabular}{cccccc}
\hline Parameter & Value $(\mathbf{m m})$ & Parameter & Value $(\mathbf{m m})$ & Parameter & Value $(\mathbf{m m})$ \\
\hline $\mathrm{L}$ & 15.2 & $\mathrm{~W}_{1}$ & 3 & $\mathrm{~d}_{2}$ & 11.3 \\
1 & 11 & $\mathrm{~W}_{2}$ & 2 & $\mathrm{x}$ & 19.1 \\
$\mathrm{~L}_{\mathrm{s}}$ & 10.5 & $\mathrm{~W}$ & 0.5 & $\mathrm{y}$ & 4.3 \\
$\mathrm{~W}_{\mathrm{s}}$ & 10 & $\mathrm{~W}_{\mathrm{t}}$ & 1 & $\mathrm{p}$ & 7.3 \\
$\mathrm{~L}_{1}$ & 1 & $\mathrm{r}$ & 20.6 & $\mathrm{~g}$ & 0.5 \\
$\mathrm{~L}_{2}$ & 11 & $\mathrm{~d}_{1}$ & 16.8 & & \\
\hline
\end{tabular}

\section{CP mechanism}

A patch on a symmetric ground plane gives rise to vertically linearly polarized radiation, as the horizontally oriented current components in the symmetrical ground cancel each other [12]. For generating circular polarized radiation, the currents in the symmetric ground plane must be disturbed in such a way that a non-zero horizontal component of current in the ground plane of proper amplitude is generated. This is achieved by extending the v-shaped notch in ground plane on one side of the antenna. The amplitude of the horizontal component in the ground plane is adjusted through parametric analysis by tuning the parameters 'p' (position of $\mathrm{v}$-shaped slot) and $\mathrm{y}$ (depth of $\mathrm{v}$-shaped slot under the feed line), to be described in parametric analysis in section 2.3 .

To gain an insight into the $\mathrm{CP}$ radiation mechanism in the antenna, the current distribution on antenna surface at frequency $5.5 \mathrm{GHz}$ is analyzed as displayed in Figure 4. The orientation of surface current vector is shown for 4 different phases $90^{\circ}$ apart. At $\theta=45^{\circ}$, there exists a strong current component due to radiating patch vertically downwards, and a horizontal current component towards right due to the horizontal (non-inclined) part of the ground. The vector sum of the 2 components is indicated in Figure 4. At $\theta=135^{\circ}$, the direction of dominant current is due to the inclined part of the ground. At $\theta=225^{\circ}$, the strong vertical component due to patch orients vertically upwards, whereas the horizontal current component due to ground orients towards left (Figure 4). For $\theta=315^{\circ}$, the dominant current direction is due to inclined part of the ground. With the progression in phase, the surface current vector rotates clockwise, indicating a left-hand circularly polarized radiation being radiated along + z-direction. 


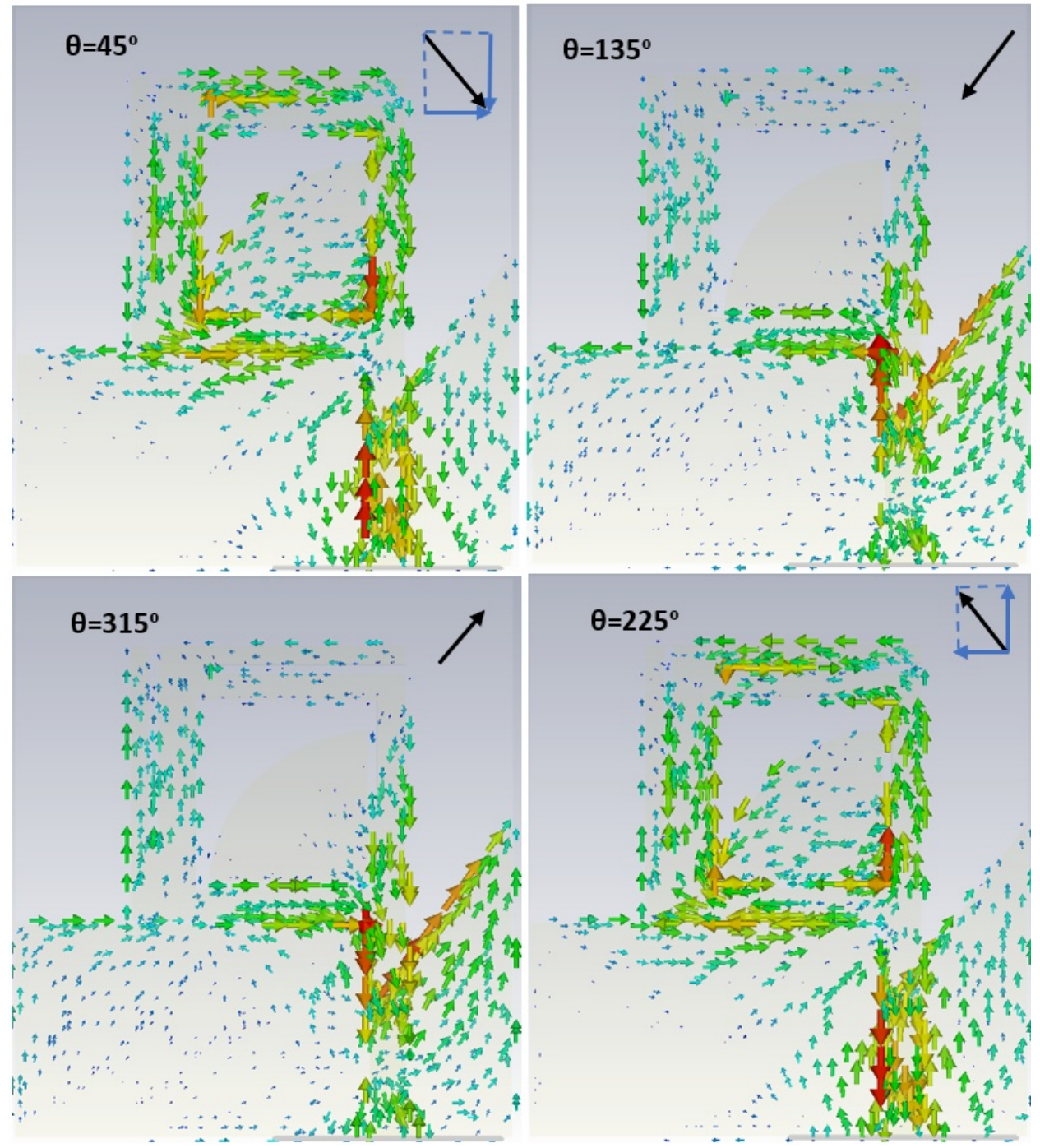

Figure 4 Current distribution on antenna surface at $5.5 \mathrm{GHz}$ (black arrows indicate the direction of net current).

\section{Parametric analysis}

In the proposed antenna design, a capacitance is formed between the top (patch) and bottom (ground) layers and FR4 acts like a dielectric in between. For exciting the requisite modes for broadband response in desired frequency range, the antenna is capacitively tuned through parametric optimization of the length of ground plane, $\mathrm{d}_{2}$.

The position of the v-shaped slot (p) and the depth of the v-shaped slot under the feed (y) have significant impact on the axial ratio and return loss coefficient of the antenna. They affect the net horizontal component of electric feed in the ground plane. This horizontal component of electric field due to asymmetrical ground combines with the vertical component of electric field due to radiating patch for generating circular polarized radiation. By tuning the parameters ' $p$ ' and ' $y$ ', the CP frequency can be tuned to generate wide axial ratio bandwidth. The impact of parameters ' $p$ ' and ' $y$ ' on CP characteristics is studied through parametric analysis. 


\section{Impact of ' $d_{2}$ '}

By varying the parameter $\mathrm{d}_{2}$, the overlap area of the ground and the antenna varies which in turn effects the gap capacitance. On increasing the value of $\mathrm{d}_{2}$, the impedance matching characteristic improves as depicted in Figure 5(a). An optimum value of $11.3 \mathrm{~mm}$ is selected for best axial ratio at $5.5 \mathrm{GHz}$ as shown in Figure 5(b). A minimum axial ratio value of 0.148 is achieved at $5.5 \mathrm{GHz}$, indicating good polarization purity. Table 2 illustrates the impact of parameter $\mathrm{d}_{2}$ on return loss and axial ratio.

Table 2 Effect of $\mathrm{d}_{2}$.

\begin{tabular}{lll}
\hline $\mathbf{d}_{\mathbf{2}}(\mathbf{m m})$ & IBW $(\mathbf{G H z})$ & ARBW $(\mathbf{G H z})$ \\
\hline 10.8 & $3.08-3.2,4.06-6.56,7.73-9.87$ & $3.68-3.71,4.42-4.68,4.72-6.22,6.55-6.81$ \\
11.3 & $3.08-3.2,4.06-9.71$ & $3.68-3.71,4.45-4.58,4.82-6.19,6.66-6.72$ \\
11.8 & $3.08-3.2,4.06-9.47$ & $3.68-3.71,4.49-4.51,4.91-6.14$
\end{tabular}

Table 3 Effect of $p$.

\begin{tabular}{lcc}
\hline $\mathbf{p}(\mathbf{m m})$ & \multicolumn{1}{c}{$\mathbf{I B W}(\mathbf{G H z})$} & ARBW $(\mathbf{G H z})$ \\
\hline 6.8 & $3.08-3.18,4.03-6.61,7.22-9.7$ & $4.47-4.66,4.75-6.17$ \\
7.3 & $3.08-3.18,4.03-9.7$ & $4.45-4.58,4.82-6.19,6.66-6.72$ \\
7.8 & $3.08-3.18,4.08-6.69,7.02-9.94$ & $4.45-4.54,4.85-6.2,6.63-6.75$ \\
\hline
\end{tabular}

\section{Impact of ' $p$ '}

The position of v-shaped notch below the feedline effects the impedance matching in the desired frequency range and hence the axial ratio as depicted in Figure 6. The value of ' $p$ ' is optimized to be 7.3 $\mathrm{mm}$ for enhancing axial ratio characteristics in desired CP band. The impact of $\mathrm{p}$ on return loss and axial ratio is summarized in Table 3.

\section{Impact of ' $y$ '}

The height of $\mathrm{v}$-shaped notch effects the impedance matching and has little impact on the AR characteristics as shown in Figure 7. The value is parametrically tuned to $4.3 \mathrm{~mm}$ for best axial ratio characteristics in desired CP band. Table 4 represents the impact of parameter ' $y$ ' on axial ratio and return loss. 


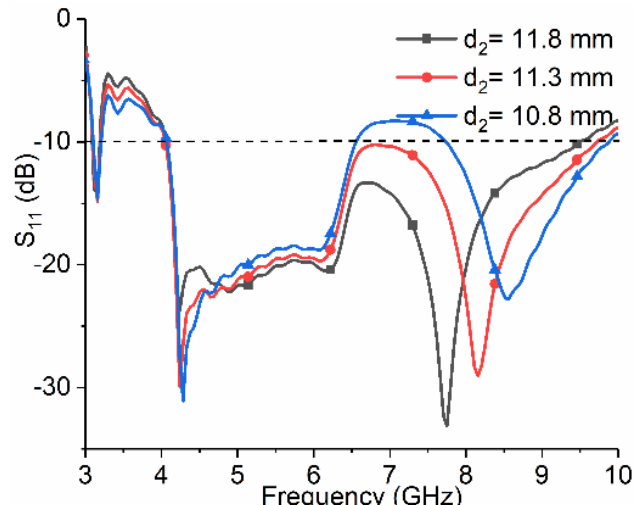

(a)

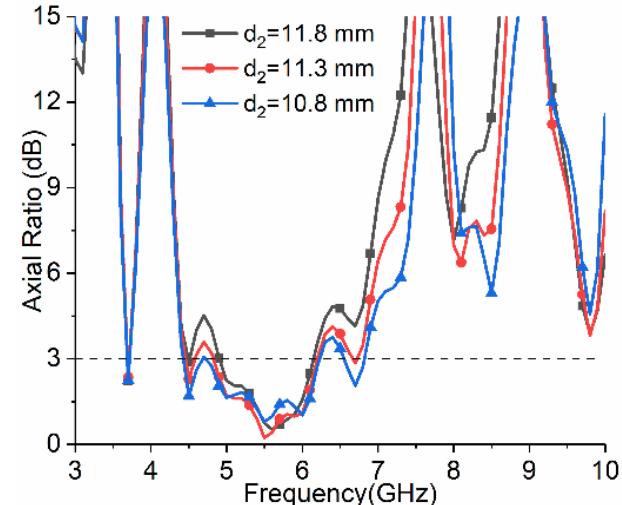

(b)

Figure 5 Impact of ' $d_{2}$ ' on (a), Return loss coefficient (b) axial ratio.

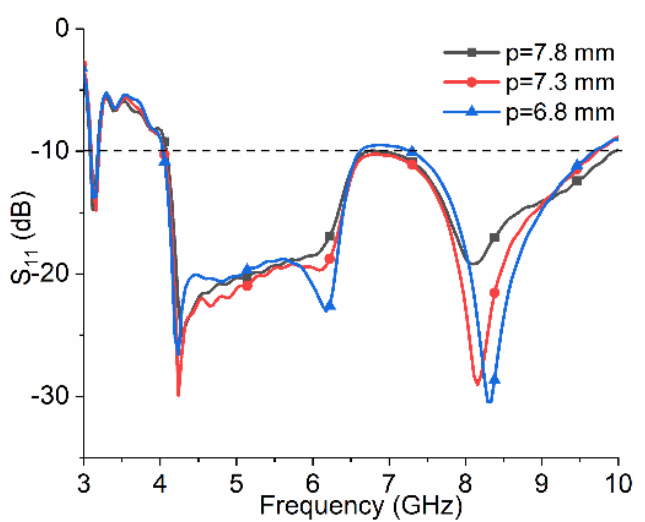

(a)

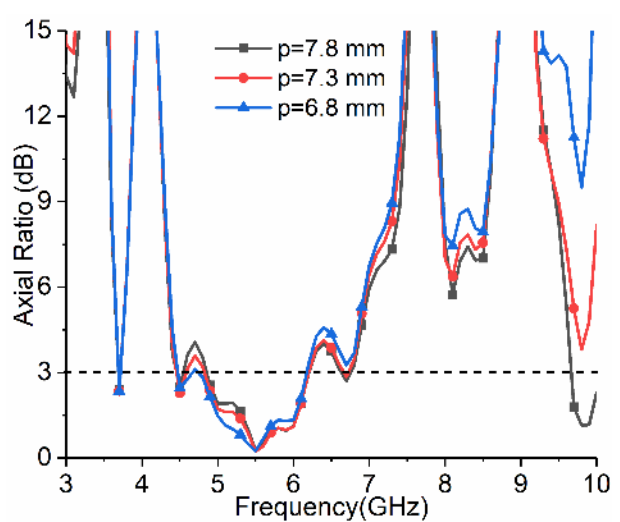

(b)

Figure 6 Impact of 'p' on (a), Return loss coefficient (b) axial ratio.

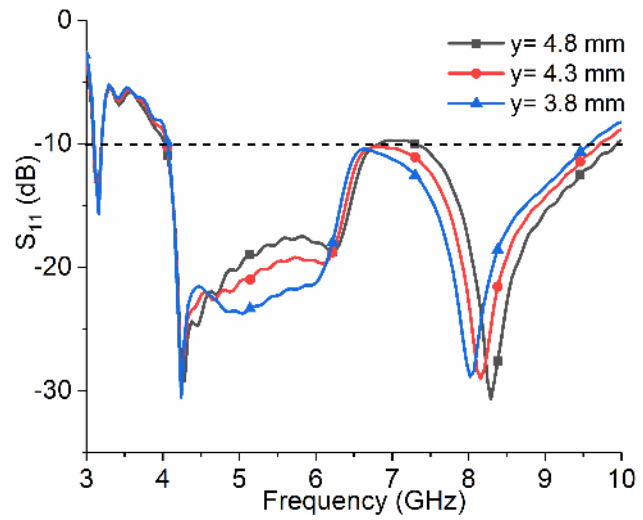

(a)

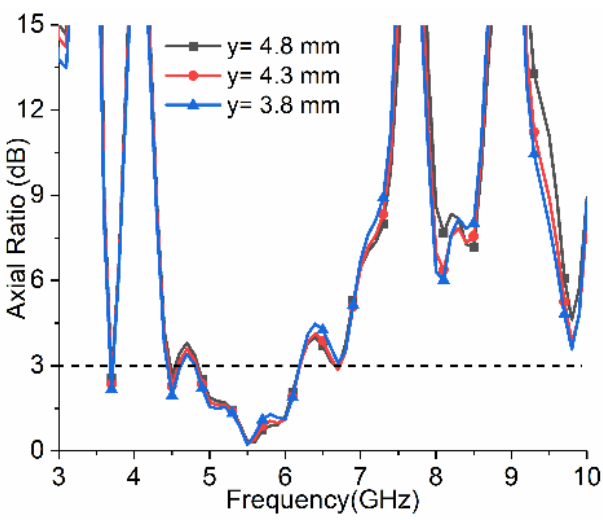

(b)

Figure 7 Impact of 'y' on (a), Return loss coefficient (b) axial ratio. 
Table 4 Effect of $y$.

\begin{tabular}{lcc}
\hline $\mathbf{y}(\mathbf{m m})$ & \multicolumn{1}{c}{ IBW $(\mathbf{G H z})$} & ARBW $(\mathbf{G H z})$ \\
\hline 3.8 & $3.09-3.19,4.06-9.58$ & $3.68-3.71,4.43-4.61,4.80-6.19$ \\
4.3 & $3.09-3.19,4.06-9.71$ & $3.68-3.71,4.45-4.58,4.82-6.19,6.67-6.71$ \\
4.8 & $3.09-3.19,4.02-6.81,7.33-9.91$ & $3.68-3.71,4.47-4.54,4.84-6.19,6.67-6.71$ \\
\hline
\end{tabular}

Axial ratio beamwidth and cross-polarization characteristics

Figure 8(a) depicts that the wide axial ratio beamwidth characteristic is stable with respect to frequency and hence the antenna is widebeam circularly polarized over a broad range of frequencies covering the WLAN band $(5.1-5.9 \mathrm{GHz})$, although some shift in the circular polarized beam is observed as expected due to rotation of radiation pattern with frequency. Moreover, the cross-polarization discrimination of the proposed circular polarized antenna is better than $15 \mathrm{~dB}$ for the above frequency range as illustrated in Figure 8(b). Cross-polarization level below $40 \mathrm{~dB}$ is observed at $5.5 \mathrm{GHz}$ frequency, making the antenna highly suited for wireless applications.

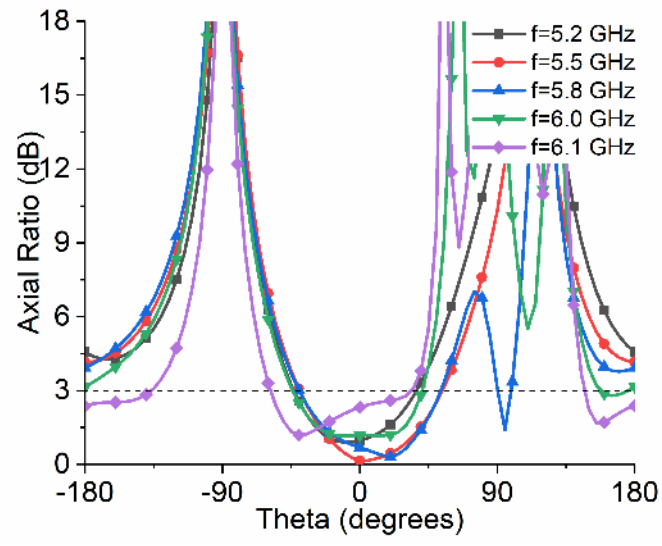

(a)

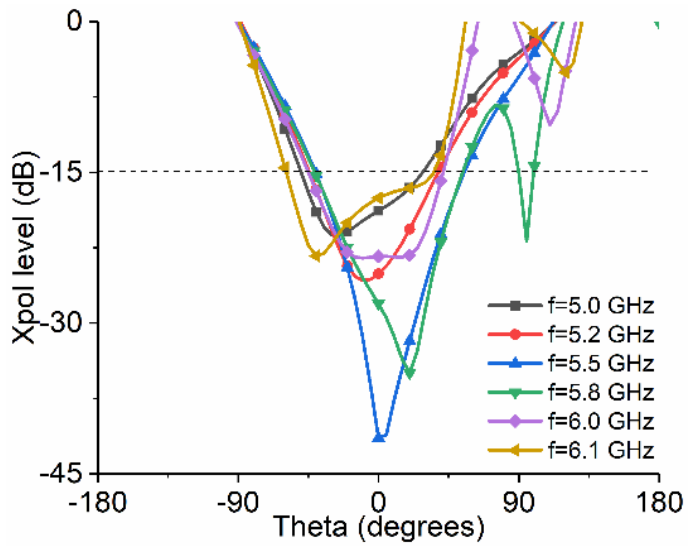

(b)

Figure 8(a) Axial ratio beamwidth, (b) cross-polarization level as a function of frequency.

\section{Results and discussion}

The simulations of the antenna are carried out in CST Microwave studio software tool, and an antenna prototype is fabricated using photolithography technique. The results are then validated through vector network analyser and anechoic chamber measurements. A comparison of measured and simulated return loss coefficients is depicted in Figure 9. 


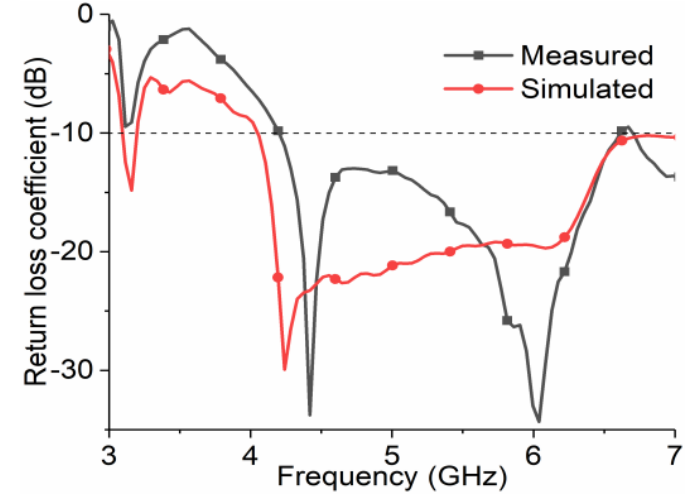

(a)

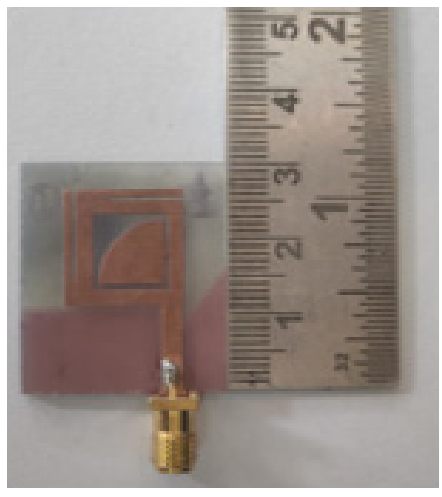

(b)

Figure 9 (a) Return loss coefficient of proposed CP antenna (b) fabricated prototype.

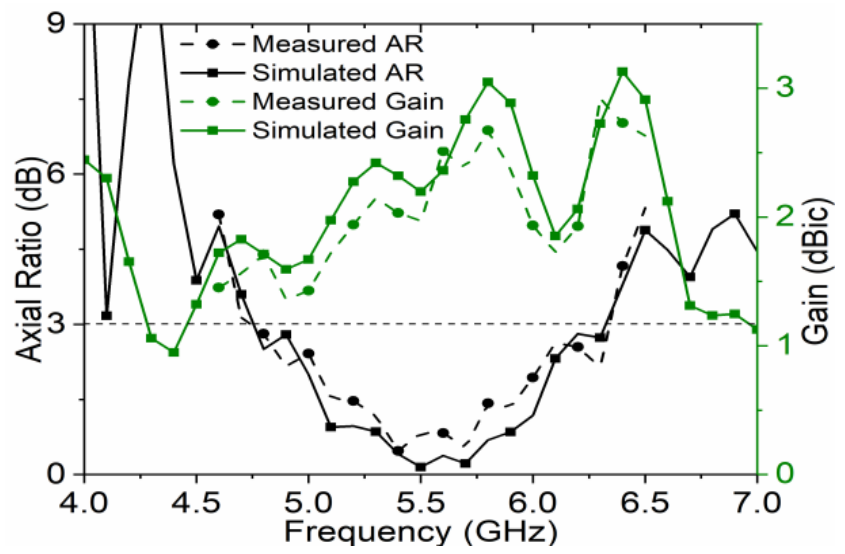

Figure 10 Simulated and measured $A R$ at boresight direction.

The impedance matching characteristic indicate measured return loss coefficient below $-13 \mathrm{~dB}$ throughout the $\mathrm{CP}$ band $(4.75-6.32 \mathrm{GHz})$. The variation in measured and simulated results can be attributed to the tolerances in fabrication and substrate properties. Measured and simulated $-10 \mathrm{~dB}$ impedance bandwidth for the proposed antenna configuration are $2.62 \mathrm{GHz}(4.2-6.82 \mathrm{GHz})$ and $3 \mathrm{GHz}$ (4 - $7 \mathrm{GHz})$, respectively.

Figure 10 compares the variation in gain and axial ratio at the boresight of the proposed $\mathrm{CP}$ antenna. The measured and simulated axial ratio bandwidth of the design are $1.5 \mathrm{GHz}(4.8-6.3 \mathrm{GHz})$ and $1.57 \mathrm{GHz}(4.75-6.325 \mathrm{GHz})$, respectively. The antenna exhibits a peak value of measured gain as 2.92 $\mathrm{dBic}$ at $6.3 \mathrm{GHz}$, with a variation of around $1.5 \mathrm{dBic}$ in the CP band. Within the WLAN band, the antenna attained a gain greater than $2 \mathrm{dBic}$.

The LHCP and RHCP radiation patterns at the centre and edge frequencies of the circular polarised band are depicted in Figure 11. The radiation patterns indicate that the measured results agree satisfactorily with the simulations. The antenna displays broad CP beamwidth and good circular polarization purity over the broad frequency range in which it exhibits $\mathrm{CP}$. The antenna half-power beamwidths have been observed to be $91.8^{\circ}$ and $237.4^{\circ}$ in E-plane and H-plane at $5.5 \mathrm{GHz}$, respectively. The antenna radiates circularly polarized radiation, RHCP along $-\mathrm{z}$ direction and LHCP along $+\mathrm{z}$ direction. 


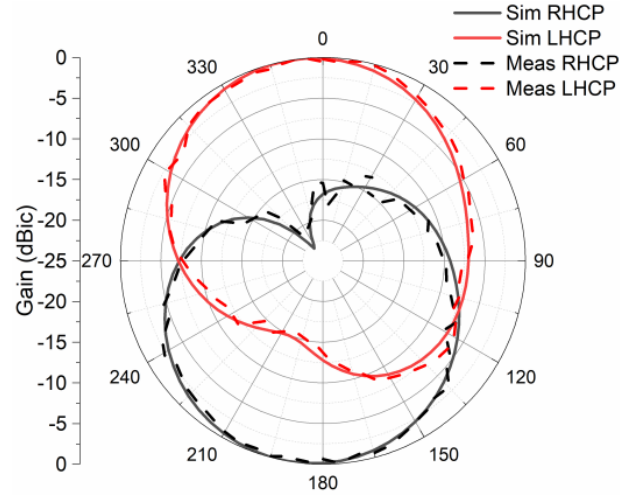

(a) $\mathrm{f}=4.8 \mathrm{GHz}$, E-plane

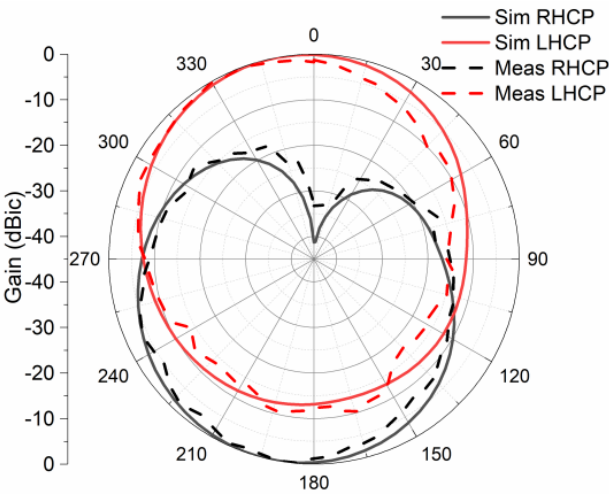

(c) $\mathrm{f}=5.5 \mathrm{GHz}$, E-plane

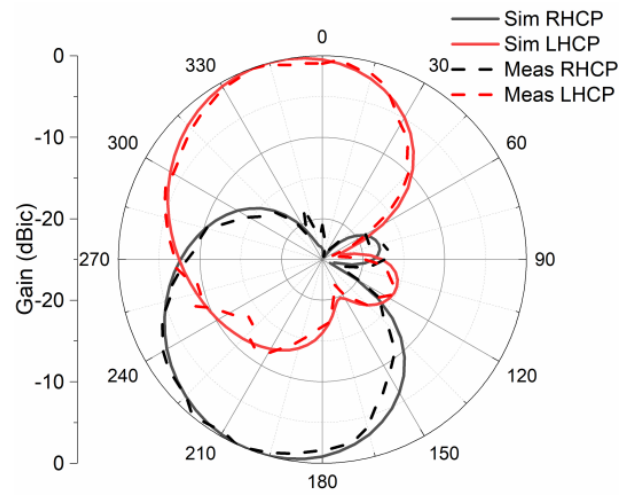

(e) $\mathrm{f}=6 \mathrm{GHz}$, E-plane

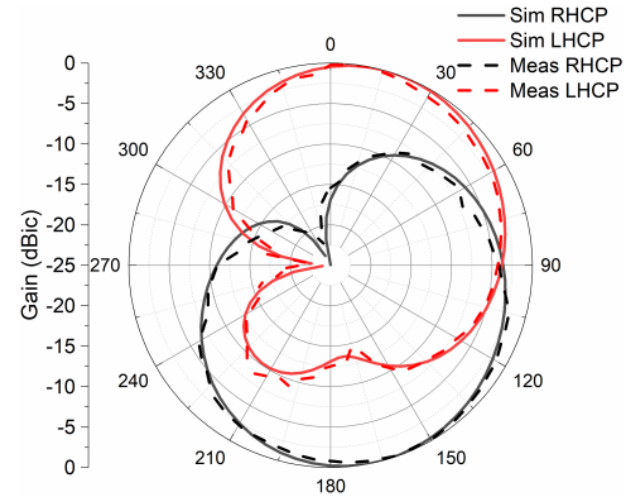

(b) $\mathrm{f}=4.8 \mathrm{GHz}, \mathrm{H}-$ plane

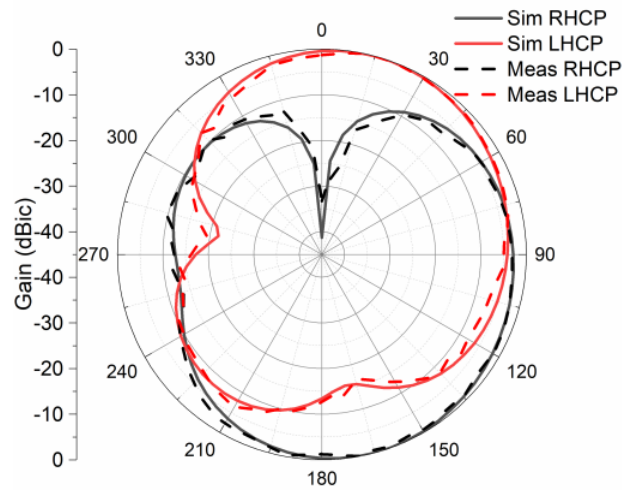

(d) $\mathrm{f}=5.5 \mathrm{GHz}$, H-plane

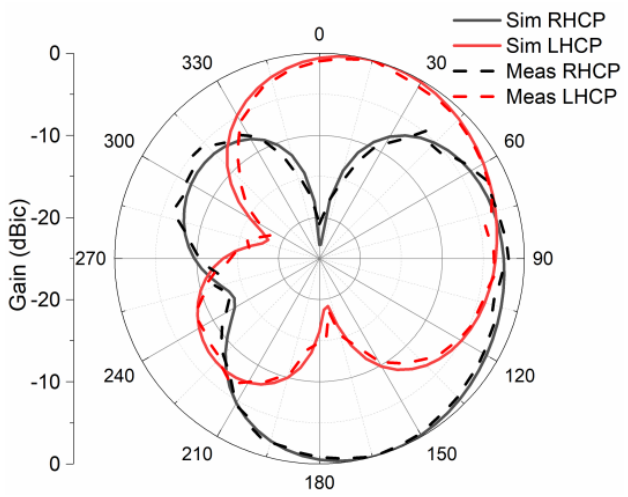

(f) $\mathrm{f}=6 \mathrm{GHz}$, H-plane

Figure 11 Normalized radiation pattern at different frequencies.

A comparison of the results thus obtained for the proposed design with some of the previously reported antennas is presented in Table 5. Though some works [15,17,20-22,25] have higher fractional IBW as compared to proposed work, [15,17,20-22,25] are electrically large. [15] achieves good AR BW 
but apart from being electrically large, is high profile (greater than quarter wavelength) hence difficult to integrate in wireless devices. Most of the designs do not mention AR Beamwidth [13,20-26], or if they are able to achieve a wide axial ratio beamwidth, they are either narrowband $[1,19]$ or they are electrically large $[15,17,18]$ or use quarter wavelength cavity for widebeam CP and are high profile $[13-15,17,18]$ making it difficult to integrate in wireless devices. It may be observed that proposed $\mathrm{CP}$ antenna design exhibits wide AR BW with wide AR beamwidth as required for wireless applications and is designed on the low cost FR4 substrate, is compact and low-profile. The above characteristics make the antenna suitable for use in multiple wireless applications including military, WLAN band HiperLAN/2 IEEE 802.11a band, WLAN frequency band and C-band uplink.

Table 5 Performance comparison with other $\mathrm{CP}$ antennas ( ${ }^{*} \mathrm{BW}$ refers to bandwidth, $\lambda_{0}$ is wavelength at center frequency).

\begin{tabular}{|c|c|c|c|c|c|c|c|c|}
\hline Ref & $\mathbf{A}$ & B & C & D & $\mathbf{E}$ & $\mathbf{F}$ & $\mathbf{G}$ & $\mathbf{H}$ \\
\hline [1] & 3.89 & $\begin{array}{c}0.54 \\
(12.6 \%)\end{array}$ & $\begin{array}{c}0.13(3.48 \\
\%)\end{array}$ & 3.48 & $\pi 0.38 \times 0.1$ & 121 & 5.1 & Taconic (CER-10) \\
\hline [13] & 2.435 & $\begin{array}{c}0.93 \\
(38.25 \%)\end{array}$ & $\begin{array}{c}0.75 \\
(28.6 \%)\end{array}$ & 24.7 & $0.97 \times 0.97 \times 0.23$ & - & 8.34 & $\begin{array}{c}\text { Crossed dipole using } \\
\text { parasitic loop resonators, } \\
\lambda / 4 \text { cavity, RT Duroid } \\
5880\end{array}$ \\
\hline [14] & 2.45 & $\begin{array}{c}1.23 \\
(50.2 \%)\end{array}$ & $\begin{array}{l}0.6 \\
(27 \%)\end{array}$ & 27 & $0.48 \times 0.48 \times 0.26$ & 90 & 6.2 & $\begin{array}{l}\text { Crossed dipole, } \lambda / 4 \\
\text { cavity, FR4 substrate }\end{array}$ \\
\hline$[15]$ & 2.08 & $\begin{array}{c}1.29 \\
(73.3 \%)\end{array}$ & $\begin{array}{c}1.06(47.7 \\
\%)\end{array}$ & 47.7 & $1.1 \times 1.1 \times 0.29$ & 100 & 8.6 & $\begin{array}{l}\text { ME dipole, } \lambda / 4 \text { cavity, } \\
\text { RT Duroid } 5880\end{array}$ \\
\hline [16] & 1.49 & $\begin{array}{c}1.17 \\
(78.3 \%)\end{array}$ & $\begin{array}{c}0.9 \\
(63.4 \%)\end{array}$ & 63.4 & $0.46 \times 0.46 \times 0.1$ & 196 & 4.5 & $\varepsilon_{\mathrm{r}}=3.38$ \\
\hline [17] & 2.15 & $\begin{array}{c}1.25 \\
(57.2 \%)\end{array}$ & $\begin{array}{c}0.65 \\
(29.9 \%)\end{array}$ & 29.9 & $1.02 \times 1.02 \times 0.1$ & 71 & $6.9 \mathrm{dBi}$ & $\begin{array}{l}\lambda / 4 \text { cavity, } \\
\text { FR4 substrate }\end{array}$ \\
\hline$[18]$ & 2.04 & $\begin{array}{c}0.94 \\
(46 \%)\end{array}$ & $\begin{array}{c}1.02(47.2 \\
\%)\end{array}$ & 42.2 & $0.81 \times 0.81 \times 0.17$ & $>100$ & 3 & $\lambda / 4$ cavity, $\varepsilon_{\mathrm{r}}=2.65$ \\
\hline [19] & 1.61 & $\begin{array}{c}0.09 \\
(5.6 \%)\end{array}$ & $\begin{array}{l}0.035(2.2 \\
\%)\end{array}$ & 2.2 & $0.32 \times 0.32 \times 0.027$ & $>140$ & 4.65 & $\begin{array}{l}\text { Slotted patch with } \\
\text { shorting pins, } \\
\varepsilon_{\mathrm{r}}=3.4\end{array}$ \\
\hline [20] & 7.83 & $\begin{array}{l}10.33 \\
(131 \%)\end{array}$ & $\begin{array}{c}3.8 \\
(63.3 \%)\end{array}$ & 63.3 & $1.04 \times 1.04 \times 0.041$ & - & $3.3 \mathrm{dBi}$ & $\begin{array}{l}\text { Hexagon-shaped open- } \\
\text { slot antenna, FR4 }\end{array}$ \\
\hline [21] & 4.5 & $\begin{array}{c}4.6 \\
(102 \%)\end{array}$ & $\begin{array}{c}4 \\
(93 \%)\end{array}$ & 93 & $0.72 \times 0.64 \times 0.024$ & - & $4 \mathrm{dBi}$ & Slot antenna, FR4 \\
\hline [22] & 5.47 & $\begin{array}{c}3.66 \\
(66.9 \%)\end{array}$ & $\begin{array}{c}3.25 \\
(57.3 \%)\end{array}$ & 57.3 & $2.06 \times 2.06 \times 0.13$ & - & 10.4 & $\begin{array}{c}\text { Crossed-dipole with } \\
\text { irregular ground plane, } \\
\varepsilon_{\mathrm{r}}=3.38,2.2\end{array}$ \\
\hline [23] & 5.5 & $\begin{array}{c}2.66 \\
(44.5 \%)\end{array}$ & $\begin{array}{c}1.45 \\
(27.5 \%)\end{array}$ & 27.5 & $0.58 \times 0.59 \times 0.1$ & - & $7.2 \mathrm{dBi}$ & $\begin{array}{l}\text { H-shaped patch with } \\
\text { RIS, RO4003 } \varepsilon_{\mathrm{r}}=3.38\end{array}$ \\
\hline [24] & 5.7 & $\begin{array}{c}2.8 \\
(48.27 \%)\end{array}$ & $\begin{array}{l}0.7,0.45 \\
(11.9 \% \\
6.8 \%)\end{array}$ & $\begin{array}{c}11.9 \\
6.8\end{array}$ & $0.95 \times 0.95 \times 0.42$ & - & $10 \mathrm{dBi}$ & $\begin{array}{l}\text { 3- dimensional dipole } \\
\text { antenna array }\end{array}$ \\
\hline [25] & 5.85 & $\begin{array}{c}6.14 \\
(105 \%)\end{array}$ & $\begin{array}{c}3.15(70.4 \\
\%)\end{array}$ & 70.4 & $1.07 \times 0.78 \times 0.031$ & - & $3.9 \mathrm{dBi}$ & $\begin{array}{c}\text { C-shaped, CPW fed slot } \\
\text { antenna, FR4 }\end{array}$ \\
\hline [26] & 5.8 & $\begin{array}{c}0.9 \\
(15.5 \%)\end{array}$ & $\begin{array}{c}0.21 \\
(3.6 \%)\end{array}$ & 3.6 & $0.67 \times 0.67 \times 0.03$ & - & $7.16 \mathrm{~dB}$ & $\varepsilon_{\mathrm{r}}=3.67$ \\
\hline [27] & 2.57 & $\begin{array}{c}0.68 \\
(26.4 \%)\end{array}$ & $\begin{array}{c}0.76(29.9 \\
\%)\end{array}$ & 26.4 & $0.72 \times 0.72 \times 0.13$ & 90 & 0.68 & $\begin{array}{c}\text { Gain enhancement of } \\
6.34 \text { dBic using } \\
\text { metasurface reflector, } \\
\text { FR4 }\end{array}$ \\
\hline
\end{tabular}




\begin{tabular}{|c|c|c|c|c|c|c|c|c|}
\hline Ref & $\mathbf{A}$ & B & C & D & $\mathbf{E}$ & $\mathbf{F}$ & G & $\mathbf{H}$ \\
\hline [28] & 2.45 & $\begin{array}{c}0.14 \\
(5.71 \%)\end{array}$ & $\begin{array}{c}0.1 \\
(4.08 \%)\end{array}$ & 4.08 & $0.24 \times 0.24 \times 0.008$ & - & - & $\begin{array}{c}\text { Ground radiation MIMO } \\
\text { antenna, FR4 }\end{array}$ \\
\hline [29] & 5.5 & $\begin{array}{c}0.61 \\
(10.86 \%)\end{array}$ & $\begin{array}{c}0.14(2.54 \\
\%)\end{array}$ & 2.54 & $0.24 \times 0.22 \times 0.04$ & - & 4.17 & $\begin{array}{c}\text { Epsilon negative TL for } \\
\text { ZOR }\end{array}$ \\
\hline [30] & 5.6 & $\begin{array}{l}1.01 \\
(18 \%)\end{array}$ & $\begin{array}{l}0.73(12.8 \\
\%)\end{array}$ & 12.8 & $0.84 \times 0.84 \times 0.038$ & - & $>8 \mathrm{dBi}$ & $\begin{array}{c}\text { F4BM350 substrate } \varepsilon_{\mathrm{r}}= \\
3.5\end{array}$ \\
\hline proposed & 5.5 & $\begin{array}{c}3 \\
(54.5 \%) \\
\end{array}$ & $\begin{array}{c}1.57(28.4 \\
\%)\end{array}$ & 28.4 & $0.56 \times 0.50 \times 0.029$ & 93.5 & 2.92 & FR4 substrate \\
\hline
\end{tabular}

Note: A: Centre frequency $(\mathrm{GHz}), \mathrm{B}$ : Absolute Impedance BW*, $\mathrm{GHz}$ (Fractional impedance*, \%), Axial ratio $\mathrm{BW}^{*}(\%)$, D: Overlapping BW* $(\%)$, E: Ground Size $\left(\lambda_{0}{ }^{3}\right)$, F: Axial ratio Beamwidth $\left({ }^{\circ}\right)$, G: Peak Gain (dBic), Substrate/ Technique used.

\section{Conclusions}

The paper includes the sequential design steps and parametric analysis of the proposed design. The proposed antenna dimensions are $31 \times 27.5 \times 1.6 \mathrm{~mm}^{3}$. The antenna is single-fed, compact, and low-profile $\left(0.029 \lambda_{0}\right)$, making it easy to integrate into portable wireless devices. A prototype of the CP antenna proposed was fabricated and tested. The antenna displays a cross-polarization discrimination better than $15 \mathrm{~dB}$ over the entire broad circularly polarized bandwidth from $4.75-6.32 \mathrm{GHz}$. The design is circular polarized over wide bandwidth (with very good cross polar discrimination over entire wide frequency range) and is having wide CP beamwidth of $93.5^{\circ}$ as required for wireless applications. The design can be used in MIMO antenna and phased array for wireless applications.

\section{Acknowledgements}

The authors are thankful to the Department of Electronics \& Communication Engineering, Women's Engineering College, Ajmer, India for providing access to the antenna measurement facility at their institute.

\section{References}

[1] $\mathrm{K} \mathrm{Ng}$, $\mathrm{CH}$ Chan and $\mathrm{K}$ Luk. Low-cost vertical patch antenna with wide axial-ratio beamwidth for handheld satellite communications terminals. IEEE Trans. Antenn. Propag. 2015; 63, 1417-24.

[2] M Wang, X Zhu, Y Guo and W Wu. Compact circularly polarized patch antenna with wide axial ratio beamwidth. IEEE Antenn. Wireless Propag. Lett. 2018; 17, 714-8.

[3] M Zhang, X Tian, X Liu and L Song. Research on a wide-beam-layered printed antenna for aerocraft telemetry system. Electromagnetics 2019; 39, 417-29.

[4] Nasimuddin, YS Anjani and A Alphones. A wide-beam circularly polarized asymmetric-microstrip antenna. IEEE Trans. Antenn. Propag. 2015; 63, 3764-8.

[5] X Chen, D Wu, L Yang and G Fu. Compact circularly polarized microstrip antenna with crosspolarization suppression at low-elevation angle. IEEE Antenn. Wireless Propag. Lett. 2017; 16, 25861.

[6] PP Sitompul, JTS Sumantyo, F Kurniawan, CE Santosa, T Manik, K Hattori, S Gao and JY Liu. A circularly polarized circularly-slotted-patch antenna with two asymmetrical rectangular truncations for nanosatellite antenna. Progr. Electromagn. Res. C 2019; 90, 225-36.

[7] A Birwal, S Singh, BK Kanaujia and S Kumar. CPW-fed ultra-wideband dual-sense circularly polarized slot antenna. Progr. Electromagn. Res. C 2019; 94, 219-31.

[8] W Mo and W Zhang. A low profile circularly polarized antenna with L-shape energy coupling slot and the s-shaped matched transmission line. Electromagnetics 2018; 38, 317-27.

[9] J Liu, X Chen, L Han, R Ma and R Yang. An omni-directional circularly polarized antenna with a low profile and wide axial-ratio beamwidth. Electromagnetics 2018; 38, 155-65. 
[10] W Hu, J Wu, Z Tang, P Fei and Y Yin. Single-feed wideband circularly polarized crossed dipole antenna with bent-slot loading. Electromagnetics 2017; 37, 162-70.

[11] KG Thomas and M Sreenivasan. A simple ultrawideband planar rectangular printed antenna with band dispensation. IEEE Trans. Antenn. Propag. 2010; 58, 27-34.

[12] K Ding, YX Guo and C Gao. CPW-fed wideband circularly polarized printed monopole antenna with open loop and asymmetric ground plane. IEEE Antenn. Wireless Propag. Lett. 2017; 16, 833-6.

[13] J Baik, T Lee, S Pyo, SM Han, J Jeong and YS Kim. Broadband circularly polarized crossed dipole with parasitic loop resonators and its arrays. IEEE Trans. Antennas. Propag. 2011; 59, 80-8.

[14] Y He, W He and H Wong. A wideband circularly polarized cross-dipole antenna. IEEE Antenn. Wireless. Propag. Lett. 2014; 13, 67-70.

[15] M Li and K Luk. A wideband circularly polarized antenna for microwave and millimeter-wave applications. IEEE Trans. Antenn. Propag. 2014; 62, 1872-9.

[16] WJ Yang, YM Pan and SY Zheng. A low-profile wideband circularly polarized crossed-dipole antenna with wide axial-ratio and gain beamwidths. IEEE Trans. Antenn. Propag. 2018; 66, 334653.

[17] Z Tu, K Jia and Y Liu. A differentially fed wideband circularly polarized antenna. IEEE Antenn. Wireless Propag. Lett. 2018; 17, 861-4.

[18] L Chen, T Zhang, C Wang and X Shi. Wideband circularly polarized microstrip antenna with wide beamwidth. IEEE Antenn. Wireless Propag. Lett. 2014; 13, 1577-80.

[19] X Qing and ZN Chen. A compact circularly polarized slotted patch antenna for GNSS applications. IEEE Trans. Antenn. Propag. 2014; 62, 6506-9.

[20] LB Pratap and A Mohan. Microstrip-fed broadband circularly polarized antenna for lower UWB. Wireless Pers. Commun. 2017; 96, 4167-75.

[21] R Kumar and N Kushwah. Design of dual band and wideband circularly polarized slot antenna for wireless applications. Int. J. Electron. Lett. 2017; 6, 377-89.

[22] WJ Yang, YM Pan, SY Zheng and PF Hu. A low profile wideband circularly polarized crosseddipole antenna. IEEE Antenn. Wireless Propag. Lett. 2017; 16, 2126-9.

[23] J Chatterjee and A Mohan. broadband circularly polarized H-shaped patch antenna using reactive impedance surface. IEEE Antenn. Wireless. Propag. Lett. 2018; 17, 625-8.

[24] TD Bui, QC Nguyen and MT Le. Novel wideband circularly polarized antenna for wireless applications. In: Proceedings of the Asia Pacific Microwave Conference, Kuala Lumpur, Malaysia. 2017, p. 430-3.

[25] K Ding, C Gao, T Yu and D Qu. CPW-fed C-shaped slot antenna for broadband circularly polarized radiation. Int. J. RF Microw. Comput. Eng. 2015; 25, 739-46.

[26] S Maddio. A compact circularly polarized antenna for $5.8 \mathrm{GHz}$ intelligent transportation system. IEEE Antenn. Wireless Propag. Lett. 2017; 16, 533-6.

[27] M Ameen, O Ahmad and RK Chaudhary. Wideband circularly-polarised high-gain diversity antenna loaded with metasurface reflector for small satellite applications. Electron. Lett. 2019; 55, 829-31.

[28] L Qu, H Piao, Y Qu, HH Kim and H Kim. Circularly polarised MIMO ground radiation antennas for wearable devices. Electron. Lett. 2018; 54, 189-90.

[29] M Ameen and RK Chaudhary. Metamaterial-based circularly polarised antenna employing ENG-TL with enhanced bandwidth for WLAN applications. Electron. Lett. 2018, 54, 1152-4.

[30] M Ameen and RK Chaudhary. Metamaterial-based wideband circularly polarised antenna with rotated V-shaped metasurface for small satellite applications. Electron. Lett. 2019; 55, 365-6. 